\title{
Diabetes Management and $N$ of 1 Trials In Silico
}

\author{
P. Augstein*, L. Vogt and E. Salzsieder
}

Institute of Diabetes “Gerhardt Katsch” Karlsburg e.V.. Greifswalder Str.11e. D-17495 Karlsburg, Germany

\begin{abstract}
N$ of 1 trials are a new strategy to determine the best personal therapeutic choice for a diabetic patient. Here, we discuss the idea of performing $N$ of 1 trials in silico using the knowledge-based decision support system KADIS ${ }^{\circledR}$. This Diabetes Management System acts as interactive computer program that first generates a personal in silico copy of the glucose/insulin metabolism of the patient and then allows in silico $N$ of 1 trials in order to identify the optimal therapeutic choice for the patient. KADIS ${ }^{\circledR}$ simulates and predicts therapeutic options as medication timing, dosage, and different formulas of oral anti-diabetic drugs or insulin, as well as life style changes like exercise and reduced carbohydrate intake by the patient to support drug therapy. Self control data are the data base for KADIS ${ }^{\circledR}$. Over the past year decision support was generated for 384 diabetic patients treated by 132 general practitioners and 30 diabetes specialists. Application of KADIS $^{\circledR}$-based recommendations reduced HbAlc during the follow-up by $0.2 \%(7.1 \%$ to $6.9 \%)$ after 3 months and by $0.4 \%(7.1 \%$ to $6.7 \%)$ after 6 months in routine diabetes care. The reduction in HbA1c was strongly related to significantly improved 24-hour glucose profiles. Taken together, performing $N$ of 1 trials in silico has the potential to determine the optimal patient-oriented therapy and to predict the clinical outcomes in the management of single patients.
\end{abstract}

Keywords: Diabetes Management, in silico, KADIS ${ }^{\circledR}$, Advisory system, Decision support, Outpatient diabetes care, Continuous glucose monitoring, $\mathrm{HbA}_{1 \mathrm{c}}$.

Recently, $N$ of 1 trials were introduced as approach to determine the best personal therapeutic choice for a diabetic patient [1]. $N$ of 1 trials offer a safe, objective, evidencebased way to implement patient-oriented research to improve outcomes and satisfaction with every day clinical practice in diabetes mellitus patients. $N$ of 1 trials should be performed in a single patient as a randomized crossover study in which the patient serves as his own control [1]. Using this approach, the best personal therapy can be identified as the result of a sequence of cross-over studies.

The aim of this letter is to demonstrate the suitability of the Karlsburger Diabetes Management System $\left(\mathrm{KADIS}^{\circledR}\right)$ for $N$ of 1 trials in silico and patient-focused diabetes management. This new area of in silico studies was opened in February 2008 when the U.S. Food and Drug Administration (FDA) approved a computer simulator to model diabetes [2]. Ergo, a time, money, effort, and frustration saving strategy was accepted in principal, allowing an in silico approach to be used in $N$ of 1 trials. Salzsieder et al. [3, 4] developed the decision support system $\mathrm{KADIS}^{\circledR}$, which acts as interactive computer program that generates a personal in silico copy of the blood glucose insulin interactions of the patient investigated based on the Karlsburger model of glucose-insulin metabolism [5-9]. KADIS $^{\circledR}$ allows such therapeutic options as medication timing, dosage, and different formulas of oral anti-diabetic drugs or insulin, as well as life style changes like exercise and reduced carbohydrate intake by the patient to support

*Address correspondence to this author at the Institute of Diabetes

"Gerhardt Katsch" Karlsburg e.V.. Greifswalder Str.11e. D-17495

Karlsburg, Germany; Tel: 49-38355-68400; Fax: 49-38355-68444;

E-mail: augstein@diabetes-karlsburg.de drug therapy, to be simulated and predicted. Self control data (blood glucose monitoring and meal intake and medications) are the data base for KADIS ${ }^{\circledR}$. In order to increase the data density of self control data for blood glucose, the recently introduced continuous glucose monitoring system was used as the data source. To generate a virtual diabetic patient, KADIS $^{\circledR}$ first identifies the personal model parameter and adopts the KADIS ${ }^{\circledR}$ model to the metabolic situation of the patient. These patient-specific model parameters can create a virtual, characteristic $24-\mathrm{h}$ blood glucose profile to identify the weak points in the metabolic situation of a given person. Using this virtual copy of the patient's metabolism, the therapeutic and daily life options can be simulated in order to overcome the weak points identified based on the diabetes management guide-lines of the German Diabetes Association (DDG). The results of these simulations are summarized and the decision-support is provided as KADIS $^{\circledR}$ - based recommendations to the doctor and patient. Over the past year, Salzieder et al. [10] offered KADIS ${ }^{\circledR}$ - based decision support for 384 diabetic patients treated by 132 general practitioners and 30 diabetes specialists. Application of KADIS $^{\circledR}$ - based recommendations reduced HbAlc during the follow-up by $0.2 \%$ ( $7.1 \%$ to $6.9 \%)$ after 3 months and by $0.4 \%(7.1 \%$ to $6.7 \%)$ after 6 months in routine diabetes care. The reduction in $\mathrm{HbA} 1 \mathrm{c}$ was strongly related to significantly improved 24-hour glucose profiles [8]. The performance of $N$ of 1 trials in silico is exemplified for a patient with type 2 diabetes (Fig. 1) using the decision tree suggested by Tsapas and Matthews for treatment of hyperglycaemia [1].

Taken together, performing $N$ of 1 trials in silico has the potential to determine the optimal patient-oriented therapy combined with successful lifestyle interventions and to evaluate the clinical outcomes in the management of single patients. 


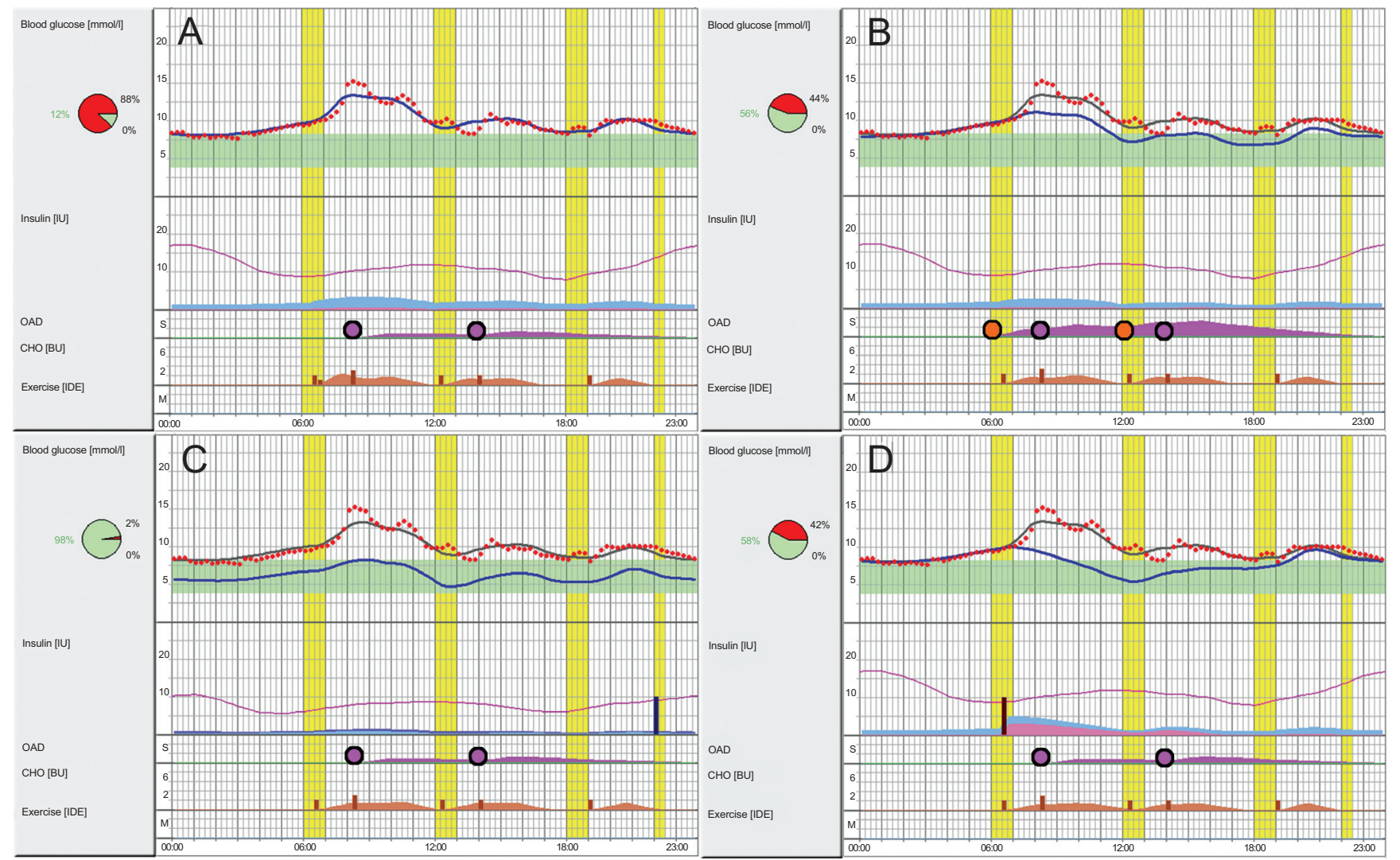

Fig. (1). Application of a $N$ of 1 trial in silico for a male type 2 diabetic patient. The patient is 67 years old and was diagnosed with diabetes in 2001 . His BMI is $28.7 \mathrm{~kg} / \mathrm{m}^{2}$ and his actual HbA1c is $8.2 \%$. He received metformin twice daily as anti-diabetic therapy. He is hyperglycaemic for most of the day which is visualised by the blood glucose curve above the green range, which represents the target range $(4.7-8.3 \mathrm{mmol} / \mathrm{l})$ and by the almost completely red quality eye. (A) The data for the KADIS ${ }^{\circledR}$ - based identification and simulations came from CGMSTM-Monitoring resulting in the red dotted line and self-control data, represented by a carbohydrate (CHO) intake of 12 bread units a day (BU, brown profile), and metformin medication (OAD, purple profile). KADIS ${ }^{\circledR}$ presents the profiles for both. The blue line in the top figure is the daily blood glucose profile estimated by KADIS ${ }^{\circledR}$. The patient didn't report regular exercise. The pink line represents the patient's insulin sensitivity over the course of the day. Below is given the endogenous insulin profile (blue). (B-D) Adoption of KADIS ${ }^{\circledR}$ on the metabolic situation of the patient and performance of a $N$ of 1 trial in silico to simulate therapeutic strategies as add-on to metformin (purple) for this patient. The grey line represents the actual blood glucose profile and the blue line is the expected daily blood glucose profile estimated by KADIS ${ }^{\circledR}$ for the tested therapy. Simulation of the decision tree suggested by Tsapas and Matthews (1) for the treatment of hyperglycaemia using pioglitazone (ACTOS) before breakfast (6:15 AM, $15 \mathrm{mg}$ ) and lunch (12:00 AM, $15 \mathrm{mg})$ and dose) (B), NPH insulin (Lantus, 10:00 PM, 8 IU) (C), and exanatide (Byetta) (6.30 AM, 10 Units) (D). In the simulations, the grey line represents the present blood glucose profile. The expected blood glucose profile belonging to the tested therapy is given in light blue. KADIS ${ }^{\circledR}$ estimates the endogenous insulin (blue) and the incretine effect (pink).

\section{ABBREVIATIONS}

CGM $=$ Continuous glucose monitoring

CGMSTM $^{\mathrm{TM}}$ Continuous glucose monitoring system

DDG $\quad=$ German Diabetes Association

KADIS $^{\circledR} \quad=$ Karlsburg Diabetes Management System

\section{REFERENCES}

[1] Tsapas A, Matthews DR. N of 1 trials in diabetes: making individual therapeutic decisions. Diabetologia 2008; 51: 921-5.

[2] JDRF. FDA Approves Computer Simulator to Model Diabetes, Test Artificial Pancreas Algorithms. Internet Communication available at http://www.jdrf.org/index.cfm?fuseaction=home.view Page\&page_id=2FE6D0FE-110A-9BB5-F888F0860E910AF3, accessed 30 October 2008.
[3] Augstein P, Vogt L, Kohnert KD, Freyse EJ, Heinke P, Salzsieder E. Outpatient assessment of Karlsburg Diabetes Management System-based decision support. Diabetes Care 2007; 30: 1704-8.

[4] Salzsieder E, Augstein P, Vogt L, et al. Telemedicine-based KADIS combined with CGMS has high potential for improving outpatient diabetes care. J Diabetes Sci Technol 2007; 1: 511-21.

[5] Rutscher A, Salzsieder E, Thierbach U, Fischer U, Albrecht G. KADIS--a computer-aided decision support system for improving the management of type-I diabetes. Exp Clin Endocrinol 1990; 95: $137-47$.

[6] Rutscher A, Salzsieder E, Fischer U. KADIS: model-aided education in type I diabetes. Karlsburg Diabetes Management System. Comput Methods Programs Biomed 1994; 41: 205-15.

[7] Salzsieder E, Albrecht G, Jutzi E, Fischer U. Estimation of individually adapted control parameters for an artificial beta cell. Biomed Biochim Acta; 43: 585-96. 
[8] Salzsieder E, Albrecht G, Fischer U, Freyse EJ. Kinetic modeling of the glucoregulatory system to improve insulin therapy. IEEE Trans Biomed Eng 1985; 32: 846-55.

[9] Salzsieder E, Albrecht G, Fischer U, Rutscher A, Thierbach U. Computer-aided systems in the management of type I diabetes: the application of a model-based strategy. Comput Methods Programs Biomed 1990; 32: 215-24.

[10] Salzsieder E, Augstein P, Vogt L, et al. Integrated diabetes health care network (IDN) in telemedicine-supported health care delivery. Diabetologia 2008; 51(Suppl. 1), S102 (A232).

(C) Augstein et al.; Licensee Bentham Open.

This is an open access article licensed under the terms of the Creative Commons Attribution Non-Commercial License (http://creativecommons.org/licenses/by$\mathrm{nc} / 3.0 /$ ) which permits unrestricted, non-commercial use, distribution and reproduction in any medium, provided the work is properly cited. 